\title{
Project Management Practices at Portuguese Startups
}

\author{
Anabela Tereso, Celina P. Leão and Tobias Ribeiro \\ Production and Systems Department / Centre ALGORITMI \\ University of Minho, Campus de Azurém, 4804-533 Guimarães, Portugal \\ \{anabelat, cpl\}@dps.uminho.pt, tobias.m.ribeiro@gmail.com
}

\begin{abstract}
Nowadays, due to the continuous changes in technology and markets, companies need to use the best project management practices to effectively manage their projects. The use of these practices however will not have the same results in different types of projects and in different organizations. The practices used by larger companies may have different results if used by smaller companies. With this in mind and focused on project management practices used by Portuguese startups, this study explores the value that project management represents for this type of companies. The study also focused on scale-ups, which are startups that have already undergone an initial phase of maturation and have more complex structures and processes, thus allowing us to see how the project management practices change with the evolution of the organization. This way, it was possible to observe that project management is seen as an essential factor within this type of organizations. These organizations seem to opt for a more agile approach to project management, thus taking advantage of the flexibility typically offered by such approaches. This type of approach seems to continue as startups mature, where there is only an increase in the formalization and complexity of project management practices and tools.
\end{abstract}

Keywords: Project Management Practices, Startups, Scale-ups.

\section{Introduction}

Organizations are increasingly focused on using Project Management (PM) methods and practices to increase the success of their projects.

According to the results presented by the Project Management Institute (PMI) Pulse of the Profession Report, the success rate of corporate projects is increasing and the average amount of money wasted on pour project performance is reducing over years. This success is due to the correct application of a professional PM system. In 2018, the results of this study demonstrated that regardless of whether using a predictive, iterative, incremental or agile approach, organizations that use some form of formal PM approach are successfully meeting their goals [1].

These benefits have already been widely discussed in the literature, but almost always in the context of PM practices associated with mature and large companies. For this study, the main focus was on small companies, with special attention to companies 
called startups. These companies are usually characterized by small activity time and they are usually looking for a position in the market [2].

To better understand this knowledge gap, the literature closest to this field is related to Small and Medium Enterprises (SMEs), and can give a perspective to better understand how the projects are treated within the universe of startups. SMEs and startups share similar characteristics and challenges. According to Murphy and Lewith [3], SMEs can be described as more flexible and closer to customers than large companies, also having a greater capacity to respond to threats and better internal communication. The differences between SMEs and large companies have profound implications, and it is possible to highlight four main differences: processes (simpler and more informal); procedures (with less standardization); structure (employees with more multi-tasking); and people (more risk-averse due to fear of failure) [4].

With the constant technological evolution and the increase in customer demand levels, organizations are forced to discover new strategies / methods of PM that can deal with these problems. The lean and agile methods are among the different methods that are able to solve these types of problems [5].

The choice of the startup type of organizations for this study is pertinent, because according to a study by Informa D\&B, entrepreneurship in Portugal has evolved considerably over the last years. The creation of startups is increasing, influencing job creation and the Portuguese business environment [6].

Taking into account the above, this paper reports on a study of the context of PM in Portuguese startups, which in turn, has as aspiration to be a contribution for this type of companies to be able to understand the importance of PM practices and what their competitors use and also to be a base for future research on these topics. The research was done trying to find answers to the following research questions: Which approaches to PM are most appropriate for Portuguese startups? What is the level of interest of Portuguese startups in the use of PM? What are the PM practices and tools used in Portuguese startups? What are the biggest limitations and challenges of Portuguese startups in PM?

\section{$2 \quad$ Literature review}

Nowadays, due to the constant technology and markets evolution, companies no longer choose to use a classic and closed management form. According to Kerzner [7], in order to respond to the changing environment, it is necessary to abandon this inefficient traditional structure and replace it with PM. Unlike traditional management, PM allows better interaction, organization, coordination and communication between different departments of a company. The result of this type of modern management provides better efficiency, effectiveness and productivity. PM helps companies to reduce time to market, to better use limited resources, to manage technology complexity, to respond to stakeholder satisfaction, and to increase their competitive advantage [8].

According to the PMI [9], PM is the application of knowledge, tools, techniques and skills to project activities, in order to meet their requirements. Besner and Hobbs [10] suggest that PM tools and techniques are practices, that if well implemented, can be 
considered as an "added value" to the organization. These practices can increase project success rates and bring competitive advantages. In another perspective, Thomas and Mullaly [11] state that the direct influence of the benefits of using project management on the profits and revenues of organizations has not yet been proven, and that this use may lead to higher costs in the short term. Most of the benefits offered by project management are associated with improvement in less tangible aspects such as stakeholder satisfaction, taking into account time, cost, quality and project processes. These benefits can help prepare organizations for future activities.

There are several standards that can help with the implementation of PM practices. Most of these standards emerged from the early 1970s, through associations dedicated to project management professionals. Some examples are: PMBOK, Prince2, ICB, P2M and APMBOK [12]. There are also agile methodologies that can be used to manage project. They emerged from software development projects, but are now used in a wide variety of project types. Generally, these methodologies are used in projects that involve a certain degree of uncertainty, risk and complexity such as new product development. Some examples of these methodologies are: Extreme Programming (XP); Scrum; Crystal; Feature Driven Development; Dynamic Systems Development Method; and Kanban [9]. Agile methodologies give more value to people, interactions, and collaboration with the client than to processes, tools, contracts, and plans. They are based on several principles: continuous innovation; product adaptation; shorter delivery time; adapting people to reliable processes and results [13].

Startups can be characterized as young enterprises, with a simple organizational structure, and informal communication. Normally, decision-making is centered on the founder or Chief Executive Officer (CEO) and is done in a style of trial and error with regard to daily business choices [14]. According to Blank and Dorf [15], a startup is not only a smallest version of a large company. It can be defined as a temporary organization in search of a scalable, repeatable and profitable business model. The European Startup Monitor (ESM) [16] considers that startups are companies under the age of ten and have high aspirations in terms of employee growth and sales. From another point of view, Ries [17] defines startup as a human institution created to design new products and services in situations of extreme uncertainty. When a startup exceeds the first initial barriers and achieves a scalable and repeatable business model, it can get a new denomination of scale-up. These companies were the focus of this study, namely on the use and relevance of project management practices.

There are not many studies on project management at startups so we searched for similar studies in SMEs. According to the studies of Turner et al. [18, 19], SMEs use simpler practices and tools and not complex standards or methodologies. They presented the following practices as the most used by SMEs: Client Requirements; Road Map; Milestones; Agile; Scrum; Work Breakdown/Activity list; Scope/Resource Schedule; Burn Down; PM Software; Risk Management; Project Office; Domain knowledge; Responsibility Assignment Matrix. These list was compared to the one collected in our study. 


\section{$3 \quad$ Research methodology}

Survey research was the strategy used to collect information. This strategy allows to question individuals on a topic and then describe their responses [20]. The researchers choose to study different startups from different areas, in order to have a more general set of results. In order to make data collection more dynamic and less standardized, the researchers found more appropriate to use semi-structured interviews. In semi-structured interviews researchers draw up a list of topics and issues to be developed, but these may vary from interview to interview. This means that the researcher may omit some questions in particular interviews, taking into account the specific organizational context that is found in relation to the research topic. The order of the questions may also vary depending on the flow of the conversation [21]. Content analysis was used to analyze the interviews [22]. The final text produced after the transcriptions and compilation of the semi-structured interviews, carried out with the support of the script developed for this purpose, was analyzed in order to obtain meanings and answers to the research questions. The categories considered coincide with the different parts defined in the interview script.

Each interview started with a brief introduction of the researcher, the topic of study, and the concise description of the purpose of the research. The script contained the main objectives of the research, starting with a first section dedicated to ascertaining the professional profile of the interviewees, being this technique used to break the ice and make them feel more comfortable. Before starting the interviews, the researcher asked permission to record the contents of the conversation, in order to later facilitate its transcription. Each interview lasted 40 minutes on average.

The script of the semi-structured interview is divided into 5 parts. The first part, as mentioned above, is dedicated to the interviewee' profile characterization in general terms, such as sex, qualifications, occupation and level of experience in PM. The second part was designed to give a brief description of organizations and identify their characteristics in terms of products, structure, risk, innovation and competitive strategy. Part three refers to the company's past and current strategy for PM and its implications for the organization's progress. Part four is intended to provide more in-depth information, observing the practices and PM tools used by the organizations, inquiring in what context they are used. The last part seeks to identify the main challenges and limitations of organizations in the area of PM, emphasizing the challenges from the point of view of flexibility and scalability.

The sample was obtained by the technique of non-probabilistic sampling by convenience and snowball [23]. In order to make the data collection richer, the researchers tried to select startups from different sectors, with different dimensions and in different contexts (e.g. 4 startups are included in incubators). In order to obtain a future perspective of PM in a startup, two of the participating organizations are organizations that have already gone through the initial startup phase and are currently in an advanced phase of scale-up. Of the 21 organizations contacted, only 9 agreed to participate in the research, resulting in an acceptance rate of approximately $43 \%$. All interviews were conducted in person and in place. All organizations received an email before the interviews were held, to know in advance the topics to be addressed. During the course of 
the interviews, the results obtained began to be similar, so the researchers felt that it would not be necessary to extend the sample of 9 organizations. Table 1 shows a brief description of the organizations that participated in the study, and Table 2 the details of the 11 interviewees of the organizations that participated in the study.

Table 1. Characterization of organizations.

\begin{tabular}{ccclc}
\hline Startup & $\begin{array}{c}\text { Years of } \\
\text { existence }\end{array}$ & $\begin{array}{c}\mathbf{N}^{\mathbf{0}} \text { of } \\
\text { employees }\end{array}$ & Company Description & Code \\
\hline Startup 1 & 3 & 6 & Treatment of statistical data; Health sector. & ST1 \\
Startup 2 & 1 & 4 & Artificial intelligence; Customer service. & ST2 \\
Startup 3 & 3 & 6 & Freight transport service. & ST3 \\
Startup 4 & 2 & 8 & Entertainment; Digital Marketing and Event Man- & ST4 \\
Startup 5 & 5 & 11 & Creative services industry; Digital and multimedia. & ST5 \\
Startup 6 & 3 & 8 & Monitoring software; Occupational health. & ST6 \\
Startup 7 & 1 & 2 & Consulting; Construction; Investments. & ST7 \\
Scaleup 1 & 10 & 32 & Digital products and services; Web design. & SCA1 \\
Scaleup 2 & 9 & $>100$ & Applications and computer software. & SCA2 \\
\hline
\end{tabular}

Table 2. Characterization of interviewees

\begin{tabular}{cll}
\hline Organization/Interviewee & Role & Experience \\
\hline ST1/1 & Chief Operating Officer (COO) & Low \\
ST1/2 & Engineer & Medium \\
ST2/1 & Chief Executive Officer (CEO) & High \\
ST3/1 & Chief Executive Officer (CEO) & High \\
ST4/1 & Founder & Medium \\
ST5/1 & Chief Executive Officer (CEO) & High \\
ST6/1 & Project Manager / Engineer & Medium \\
ST7/1 & Founder & Low \\
SCA1/1 & Project Manager & High \\
SCA1/2 & Project and Product Manager & High \\
SCA2/1 & Engineer & High \\
\hline
\end{tabular}

\section{$4 \quad$ Results and analysis}

For the characterization of interviewees' profile, gender, level of education and experience in PM, more specifically related to certification in this area, were considered. A curious result is that only $9 \%$ of respondents are female. Regarding the level of education of the interviewees, it can be considered quite high: $84 \%$ with a master's degree; $9 \%$ with a degree and $9 \%$ with secondary education. Although the high level of education, almost none of the interviewees has any type of training in the area of PM. Of the few academic contacts with this area, most was directed to PM in software development. Only two of the respondents had had some kind of contact with more traditional tools and techniques, such as the ones described in PMBOK. Only $18 \%$ of respondents had some type of certification in this area, which in turn was related to agile PM methodologies, more specifically in Scrum.

A description of the characteristics of the organizations was then required in relation to their organizational structure and decision making style, risk positioning, innovation, 
growth strategy, and their source of funding. A summary of the characteristics of the organizations is presented in Table 3.

Table 3. Summary of the characteristics of the organizations ( $\$$ startups

\begin{tabular}{|c|c|c|}
\hline Criteria & Startups & Scale-ups \\
\hline $\begin{array}{l}\text { Organizational } \\
\text { structure }\end{array}$ & Simple, flexible and informal & Formal $\% / 2$ Informal \\
\hline $\begin{array}{c}\text { Decision making } \\
\text { style }\end{array}$ & $\begin{array}{l}\text { Performed informally; centralized } \\
\text { in founders or CEO. } \\
\text { Decentralized }\end{array}$ & $\begin{array}{c}\text { Decentralized } \\
\text { Centralized }\end{array}$ \\
\hline Risk positioning & $\begin{array}{c}\text { High risk } \\
\text { AfA여영 }\end{array}$ & Low risk; comfortable situation \\
\hline Innovation & $\begin{array}{l}\text { Something crucial } \\
\text { A\&A } 4 \text { \& } 4 \text { A }\end{array}$ & Something important $/ 2$ \\
\hline Growth strategy & $\begin{array}{l}\text { In terms of market penetration } \\
\text { through internationalization, or by } \\
\text { increasing the customer base in the } \\
\text { respective markets }\end{array}$ & $\begin{array}{l}\text { Related to the business model } \\
\text { Increase number of employees }\end{array}$ \\
\hline Source of funding & 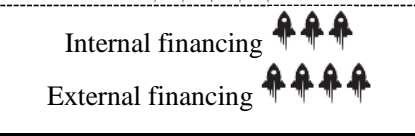 & Sustainable \\
\hline
\end{tabular}

A simple structure, an informal environment, and a centralized decision making are characteristics that are shared by all startup organizations, regardless of the industry to which they belong. In the case of scale-ups, it was noticed that with the increase of the organization it is natural that the decision making becomes more decentralized and the environment more formal.

All startups, regardless of their context, have confirmed that the risk factor is something that is always present in their daily life. For scale-ups, as the organization gets a more scalable business model, the risk decreases.

Confirming the characteristics presented by Ries [17], innovation was seen by all startups as an essential element of the organization, evidenced in the characteristics of the product/service or in the business model. The importance of this factor seemed to be maintained in the scale-ups represented in the study, demonstrating that innovation is a value that seems to be transversal throughout the maturation of the startup.

In terms of growth, not all startups have shown a huge ambition to increase the number of employees and turnover as referred by the European Startup Monitor [16]. Most startups were just looking to penetrate their respective markets through internationalization or by increasing the customer base in the respective markets.

Lastly, one surprising fact that has emerged in this sample was the fact that some startups are using a type of internal financing, that is, the founders are willing to take high risks. The scale-ups show to be more sustainable on this matter. 
Regarding the strategy of companies in relation to PM, we asked about: the type of projects they had (internal/external); what was their official PM structure; the culture of the organization (formal/informal PM); vision of the utility of PM; lean startup concepts application; and staff certified with PM. This is summarized in Table 4.

Table 4. Summary of the strategies in relation to PM

\begin{tabular}{|c|c|c|}
\hline Criteria & Startups & Scale-ups \\
\hline Projects & $\begin{array}{c}\text { Internal } \$ \\
\text { External } \$ \text { \& } \$ \text { \& } \\
\text { Internal and External } \$ \text { \& }\end{array}$ & Internal and External \\
\hline Official PM system & $\begin{array}{l}\text { Agile or Scrum Methodologies } \$ \$ \$ A \\
\text { Not using any methodology or standard } \\
\end{array}$ & Scrum \\
\hline $\begin{array}{c}\text { Culture of the organiza- } \\
\text { tion } \\
\text { (formal / informal PM) }\end{array}$ & $\begin{array}{c}\text { Informal } \$ \& \& \& \& \\
\text { Formal } \$\end{array}$ & Formal \\
\hline $\begin{array}{l}\text { PM, competitive strategy } \\
\text { / competitive advantage }\end{array}$ & $\begin{array}{l}\text { Useful in the organization and its value as } \\
\text { a competitive tool }\end{array}$ & An indispensable tool for \\
\hline Lean Startup & $\begin{array}{c}\text { Concepts related to Lean Startup identified } \\
\text { and consciously applied } \\
\text { Unconscious application }\end{array}$ & \\
\hline Staff certified with PM & $\begin{array}{c}\text { Certification is not an essential element for } \\
\text { organization }\end{array}$ & $\begin{array}{l}\text { Certification in } \mathrm{PM} \text { as an } \\
\text { important element for the } \\
\text { organization }\end{array}$ \\
\hline
\end{tabular}

These results show that PM is important to startups and scale-ups, being more informal in the startups and tending to be more formal for scale-ups, and seen as useful for the startups and indispensable for the scale-ups, where PM certification is also considered relevant. Lean startup is applied in some of the organizations studied.

The PM practices most used in the studied organizations are shown in Table 5. In this results we can highlight the difference between the use of less formalized agile methodologies for the companies with less maturity and formal Scrum or Kanban methodologies used by the companies with more maturity. The same applies to risk management and the use of PM software.

Compared to the study of Turner et al. $[18,19]$ on practices in SMEs the difference was that in SMEs are used two practices not referred by the organizations under our study, namely Project Office and Responsibility Assignment Matrix. But in our study Kanban was referred as a practice not present in the SMEs study.

Finally, Table 6 shows a summary of the limitations and challenges in the PM strategy felt by the studied organizations. It is visible the limitations in the application of PM practices for startups and how it decreases when the organization grows, but all considered important to improve PM practices in their organizations. 
Table 5. PM practices most used in the studied organizations

\begin{tabular}{cccccccccc}
\hline Practices & ST1 & ST2 & ST3 & ST4 & ST5 & ST6 & ST7 & SCA1 & SCA2 \\
\hline Client Requirement & $\mathrm{X}$ & $\mathrm{X}$ & $\mathrm{X}$ & $\mathrm{X}$ & $\mathrm{X}$ & $\mathrm{X}$ & $\mathrm{X}$ & $\mathrm{X}$ & $\mathrm{X}$ \\
Road Map & $\mathrm{X}$ & & $\mathrm{X}$ & & $\mathrm{X}$ & $\mathrm{X}$ & & $\mathrm{X}$ & $\mathrm{X}$ \\
Milestones & & & & $\mathrm{X}$ & & & $\mathrm{X}$ & & \\
WBS/Activity list & $\mathrm{X}$ & & $\mathrm{X}$ & $\mathrm{X}$ & $\mathrm{X}$ & $\mathrm{X}$ & & $\mathrm{X}$ & $\mathrm{X}$ \\
Agile & $\mathrm{X}$ & & $\mathrm{X}$ & & $\mathrm{X}$ & $\mathrm{X}$ & & $\mathrm{X}$ & $\mathrm{X}$ \\
Scrum & & & & & & $\mathrm{X}$ & & $\mathrm{X}$ & $\mathrm{X}$ \\
Kanban & $\mathrm{X}$ & $\mathrm{X}$ & & & $\mathrm{X}$ & & & $\mathrm{X}$ & $\mathrm{X}$ \\
Scope/Resource Schedule & & $\mathrm{X}$ & & $\mathrm{X}$ & & & $\mathrm{X}$ & & \\
Burndown & & & & & & $\mathrm{X}$ & & $\mathrm{X}$ & $\mathrm{X}$ \\
Domain Knowledge & & & & $\mathrm{X}$ & & $\mathrm{X}$ & $\mathrm{X}$ & & $\mathrm{X}$ \\
Risk Management & & & & & $\mathrm{X}$ & $\mathrm{X}$ & & $\mathrm{X}$ & $\mathrm{X}$ \\
PM Software & $\mathrm{X}$ & & & & $\mathrm{X}$ & \\
\hline
\end{tabular}

Table 6. Summary of the limitations and challenges in the PM strategy

\begin{tabular}{|c|c|c|}
\hline Criteria & Startups & Scale-ups \\
\hline \multirow[t]{2}{*}{$\begin{array}{c}\text { Limitations in application of } \\
\text { PM }\end{array}$} & \multirow[t]{2}{*}{$\begin{array}{l}\text { It has drawbacks } \\
\text { \&4예예 }\end{array}$} & $\begin{array}{l}\text { There is a decrease in the limitations } \\
\text { of PM as the organization grows }\end{array}$ \\
\hline & & 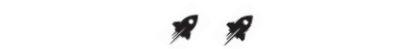 \\
\hline \multirow[t]{2}{*}{$\begin{array}{l}\text { Need to improve PM in the or- } \\
\text { ganization }\end{array}$} & \multirow[t]{2}{*}{ Yes } & $\begin{array}{l}\text { There is always room for improving } \\
\text { PM in the organization (continuous } \\
\text { process) }\end{array}$ \\
\hline & & 米 \\
\hline Scalability of PM strategy & 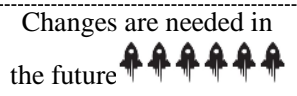 & Scalability has to be planned \\
\hline
\end{tabular}

\section{$5 \quad$ Conclusions and future research}

The concepts of innovation, risk and flexibility are present in the definition of what it means to be a startup. These young companies need to have the innovative ability to generate value for customers and to penetrate their respective markets. The search for a business model that is scalable and profitable carries risks, thus creating an environment of uncertainty that involves the company in this early phase of the organization's life cycle. Startups seek to receive constant feedback from the market, which in turn will have an influence on the way PM is developed in the organization. Startups require a lighter approach to project management, which promotes flexibility and iterations, rather than more structured and sequential approaches, characteristic of more traditional approaches to project management. In this way, it is not surprising to find in this research, and based on data gathered during semi-structured interviews to 7 startups and 2 scale-ups, that startups opt more for agile strategies for the development of their projects, since it is the approach most compatible with the cycle of experimentation characteristic of this type of companies.

In the universe of Portuguese startups, the value of the scientific area of PM seems to be well founded. Portuguese startups are managed through the use of projects, and $\mathrm{PM}$ is seen as essential to the organizations, although their low level of maturity. There 
is not much academic knowledge about some concepts of this scientific area and certification of employees is seen as not fundamental. However, it is our believe that PM can represent a competitive advantage for the young companies like startups and scaleups in Portugal, since it provides tools and techniques capable of managing projects scope, time and cost, besides other areas such as quality, stakeholders and risk, so important for this type of organizations.

Most Portuguese startups seem to opt for project management practices and tools with more agile features like Kanban and Scrum. The degree of formalization of the practices and tools of project management seemed to vary with the maturity of the organizations. The organizations under study revealed to use the following practices: Client Requirement; Road Map; Milestones; WBS/Activity list; Agile; Scrum; Kanban; Scope/Resource Schedule; Burndown; Domain Knowledge; Risk Management and PM Software. Compared to a previous study on SMEs [18, 19], there are similar tools being used. Organizations just did not refer the use of Project Office and Responsibility Assignment Matrix as SMEs seem to use. But Kanban was a practice referred in our study that is not mentioned in the SMEs study.

The main limitations observed in the context of the Portuguese startups in the application of PM are related to the rigidity, cost and time associated with some PM practices, which are the main reasons for their more informal use in an initial phase of the startup. The lack of resources is also a problem of Portuguese startups, which makes them reluctant to invest on the area of PM, at an early stage. The more mature Portuguese startups present in the study are a proof that investing in PM can be a crucial part of an organization's development.

A limitation of this study was the size and the geographic location of the sample, so future studies on this matter are important to consolidate conclusion and information gathered on the subject that may be used as a reference for startups. In future work it might also be interesting to isolate circumstances and study only startups belonging to an incubator or a particular industry.

Acknowledgements. This work has been supported by FCT - Fundação para a Ciência e Tecnologia within the Project Scope: UID/CEC/00319/2019.

\section{References}

1. PMI: Success in Disruptive Times. In: Pulse of the Profession 2018. Project Management Institute (2018).

2. Racolta-Paina, N.-D., Mone, S.-D.: Start-up marketing: how to become a player on the B2B services market in Romania. Management \& Marketing. 4, 63-78 (2009).

3. Murphy, A., Ledwith, A.: Project Management Tools and Techniques in High-Tech SMEs in Ireland. High Technology Small Firms Conference. (2006).

4. Ghobadian, A., Gallear, D.: TQM and organization size. International Journal of Operations \& Production Management. 17, (1997).

5. Rodríguez, P., Mäntylä, M., Oivo, M., Lwakatare, L.E., Seppänen, P., Kuvaja, P.: Advances in Using Agile and Lean Processes for Software Development. Advances in 
Computers. (2018).

6. Informa D\&B: O Empreendedorismo em Portugal. (2017).

7. Kerzner, H.: Project management best practices: Achieving global excellence. John Wiley \& Sons (2018).

8. Patanakul, P., Iewwongcharoen, B.: An empirical study on the use of project management tools and techniques across project life-cycle and their impact on project success. Journal of General. (2010).

9. PMI: A Guide to the Project Management Body of Knowledge (PMBOK GUIDE). Project Management Institute, Pennsylvania (2017).

10. Besner, C., Hobbs, B.: The Perceived Value and Potencial Contribution of Project Management Practices to Project Success. Project Management Journal. 37, 37-48 (2006).

11. Thomas, J., Mullaly, M.: Understanding the value of project management: First steps on an international investigation in search of value. Project Management Journal. 38, 7489 (2007).

12. Sanjuan, A.G., Froese, T.: The application of project management standards and success factors to the development of a project management assessment tool. Procedia-Social and Behavioral Sciences. 74, 91-100 (2013).

13. Highsmith, J.: Agile project management. Addison-Wesley Professional (2004).

14. Lester, D.L., Parnell, J.A., Carraher, S.: Organizational Life Cycle: a Five-Stage Empirical Scale. The International Journal of Organizational Analysis. 11, 339-354 (2003).

15. Blank, S., Dorf, B.: The Startup Owner's Manual: The Step-By-Step Guide for Building a Great Company. K\&S Ranch, Inc. (2012).

16. Kollmann, T., Stöckmann, C., Hensellek, S., Kensbock, J.: European Startup Monitor. (2016).

17. Ries, E.: The Lean Startup: How Today's Entrepreneurs Use Continuous Innovation to Create Radically Successful Businesses. (2011).

18. Turner, R., Ledwith, A., Kelly, J.: Project management in small to medium-sized enterprises: Matching processes to the nature of the firm. International Journal of Project Management. 28, 744-755 (2010).

19. Turner, R., Ledwith, A., Kelly, J.: Project management in small to medium-sized enterprises: Tailoring the practices to the size of company. Management Decision. 50, 942-957 (2012).

20. Jackson, S.L.: Research Methods and Statistics: A Critical Thinking Approach. Cengage Learning (2015).

21. Saunders, M., Lewis, P., Thornhill, A.: Research Methods for Business Students. Education, Pearson, ISBN: 978-0-273-71686-0. (2009).

22. Huberman, A.M., Miles, M.B.: Qualitative Data Analysis: An Expanded Sourcebook. Sage publications (1994).

23. Robinson, O.C.: Sampling in Interview-Based Qualitative Research: A Theoretical and Practical Guide. Qualitative Research in Psychology. 11, 25-41 (2014). 